East European Journal of Physics

East Eur. J. Phys. 4. 87-92(2018)

DOI:10.26565/2312-4334-2018-4-10

PACS: $61.50 . \mathrm{Ah}, 64.10 .+\mathrm{h}$

\title{
INVESTIGATION OF THE LIQUIDUS LINE ON THE Fe-B STATE DIAGRAM
}

\author{
DD.Yu. Filonenko \\ State Establishment "Dnipropetrovsk Medical Academy of Health Ministry of Ukraine" \\ 9, Vernadsky Str., Dnipro, 49044, Ukraine \\ E-mail:natph2016@gmail.com \\ Received 29 October 2018, revised 19 November 2018
}

In this paper we determine the crystallization temperature of a melt of the Fe-B system depending on the boron content and. The thermodynamic properties of the boron-bearing phases are studied. The investigation was performed for alloys with the boron content of 2.0-4.2.0\% (wt.), the rest is iron. The smelting of Fe-B system alloy was carried out in a furnace in alundum saggers in the argon atmosphere. The cooling rate of as-cast alloys was $10 \mathrm{~K} / \mathrm{s}$. To ascertain the structural condition of alloys we used the microstructure analysis, the differential thermal and the X-ray structural analyses. In the paper, based on experimental data for the Fe-B alloys, we determined the crystallization temperatures of alloys under consideration, depending on the content of boron in the alloy. In addition, we revealed that the $\gamma-\mathrm{Fe}+\mathrm{Fe}_{2} \mathrm{~B}$ eutectic transformation occurs at the temperature of $1441 \mathrm{~K}$ and at the boron content of $3.8 \%$ (wt.). To determine the thermodynamic functions of the phases we used the quasi-chemical method. With accounting for the contribution of the first degree approximation of the high-temperature expansion for the thermodynamic potential we derived expressions for the free energy of the melt of the binary Fe-B alloy, the boron-doped austenite and the $\mathrm{Fe}_{2} \mathrm{~B}$ boride. The expressions obtained for the free energy potential and the chemical potential of the melt of the binary $\mathrm{Fe}-\mathrm{B}$ alloy, the austenite and the $\mathrm{Fe}_{2} \mathrm{~B}$ boride enable to obtain the $\mathrm{Fe}-\mathrm{B}$ phase diagram liquidus boundaries. The calculations performed in this paper made it possible to obtain the numerical values of the crystallization temperature of the alloy, depending on the boron content, and to determine the temperature of the $\gamma-\mathrm{Fe}+\mathrm{Fe}_{2} \mathrm{~B}$ eutectic transformation and the boron content, at which this transformation takes place in the alloy. Such an approach allows describing most completely from the thermodynamic point of view the crystallization process and the eutectic transformation. The results of the calculations obtained in this paper are in good agreement with the experimental data.

KEYWORDS: melt, overheating of alloy above the liquidus line, $\mathrm{Fe}-\mathrm{B}$ system alloys, $\mathrm{Fe}_{2} \mathrm{~B}$ iron boride

\section{ДОСЛІДЖЕННЯ ЛІНІЇ ЛІКВІДУСУ НА ДІАГРАМІ СТАНУ Fе-В Н.Ю. Філоненко \\ Д3 «Дніпропетровська державна медична академія МОЗ України» 49044, Україна, м. Дніпро, вул. Володимира Вернадського, 9}

У роботі встановлено температуру кристалізації розплаву системи $\mathrm{Fe}-\mathrm{B}$ в залежності від вмісту бору та вивчено термодинамічні властивості фаз, що містять бор. Дослідження проводили на сплавах з вмістом бору 2,0-4,2,0 \% (мас.), решта - залізо. Виплавку сплавів системи Fe-B проводили в печі в алундових тиглях в атмосфері аргону. Швидкість охолодження сплавів після лиття складала $10 \mathrm{~K} / \mathrm{c}$. Для визначення структурного стану сплавів використовували мікроструктурний, рентгеноструктурний та диференційний термічний аналізи. У роботі за результатами експериментальних даних для сплавів системи Fe-B було визначено температури їх кристалізації в залежності від вмісту бору в сплаві. Окрім цього, визначено, що евтектичне перетворення $\gamma$-Fe+Fe 2 B відбувається при температурі 1441 К та вмісті бору 3,8 \% (мас.). Для визначення термодинамічних функцій фаз використовувався квазіхімічний метод. 3 урахуванням внеску наближення першого ступеня високотемпературного розвинення термодинамічного потенціалу було отримано вирази для вільної енергії розплаву бінарного сплаву $\mathrm{Fe}-\mathrm{B}$, аустеніту, легованого бором, та бориду $\mathrm{Fe}_{2} \mathrm{~B}$. Отримані вирази для вільної енергії та хімічного потенціалу розплаву бінарного сплаву $\mathrm{Fe}-\mathrm{B}$, аустеніту та бориду $\mathrm{Fe}_{2} \mathrm{~B}$ дозволили визначити розташування лінії ліквідусу на діаграмі стану Fe-B. Проведені в даній роботі розрахунки дали змогу отримати числові значення температури кристалізації сплаву в залежності від вмісту бору, визначити температуру евтектичного перетворення $\gamma$-Fe+Fe $2 \mathrm{~B}$ та вміст бору в сплаві, при якому відбувається це перетворення. Використаний у даній роботі підхід робить можливим надання найбільш повного з термодинамічної точки зору опису процесу кристалізації та евтектичного перетворення. Отримані результати розрахунків досить добре узгоджуються з експериментальними даними.

КЛЮЧОВІ СЛОВА: розплав, перегрів сплаву вище лінії ліквідусу, сплави системи Fe-B, борид заліза $\mathrm{Fe}_{2} \mathrm{~B}$

\section{ИССЛЕДОВАНИЕ ЛИНИИ ЛИКВИДУСА НА ДИАГРАММЕ СОСТОЯНИЯ Fе-В Н.Ю. Филоненко}

ГУ «Днепропетровская государственная медичинская академия МОЗ Украиныл» 49044, Украина, г. Днепр, ул. Владимира Вернадского, 9

В работе установлена температура кристаллизации расплава системы $\mathrm{Fe}-\mathrm{B}$ в зависимости от содержания бора и изучены термодинамические свойства борсодержащих фаз. Исследования проводились на сплавах с содержанием бора 2,0-4,2,0\% (мас.), остальное - железо. Выплавка сплавов проводилась в печи в алундовых тиглях в атмосфере аргона. Скорость охлаждения сплавов после литья составила $10 \mathrm{~K} / \mathrm{c}$. Для определения структурного состояния сплавов использовали микроструктурный, рентгеноструктурный и дифференциальный термический анализы. В работе по результатам экспериментальных данных для сплавов системы Fe-B были установлены температуры их кристаллизации в зависимости от содержания бора в сплаве. Кроме этого, было установлено, что эвтектическое превращение $\gamma$ - $\mathrm{Fe}+\mathrm{Fe}_{2} \mathrm{~B}$ происходит при температуре 1441 К и содержании бора 3,8 \% (мас.). Для определения термодинамических функций фаз использовался квазихимический метод. С учетом приближения первой степени высокотемпературного разложения термодинамического потенциала были получены выражения для свободной энергии расплава бинарного сплава Fe-B, аустенита, легированного 
бором, и борида $\mathrm{Fe}_{2} \mathrm{~B}$. Полученные выражения для свободной энергии и химического потенциала для расплава бинарного сплава $\mathrm{Fe}-\mathrm{B}$, аустенита и борида $\mathrm{Fe}_{2} \mathrm{~B}$ позволили определить расположение линии ликвидуса на диаграмме состояния $\mathrm{Fe}-\mathrm{B}$. Проведенные в данной работе расчеты позволили получить численные значения температуры кристаллизации сплава в зависимости от содержания бора,определить температуру эвтектического превращения $\gamma$ - $\mathrm{Fe}+\mathrm{Fe}_{2} \mathrm{~B}$ и содержание бора в сплаве, при котором происходит данное превращение. Использованный в данной работе подход позволяет дать наиболее полное с термодинамической точки зрения описание процесса кристаллизации и эвтектического превращения. Полученные результаты расчетов достаточно хорошо согласуются с экспериментальными данными.

КЛЮЧЕВЫЕ СЛОВА: расплав, перегрев сплава выше линии ликвидуса, сплавы системы Fe-B, борид железа Fе2В

Сплави системи $\mathrm{Fe}-\mathrm{B}$ досліджуються кілька десятиліть, але наразі нема єдиної думки щодо фазового складу та температур фазових перетворень. Відомо, що в системі Fe-B відбувається утворення евтектики $\gamma$ $\mathrm{Fe}+\mathrm{Fe}_{2} \mathrm{~B}$, але різні автори наводять на діаграмі стану системи $\mathrm{Fe}-\mathrm{B}$ різні температури цього перетворення. Наприклад, автори робіт [1-3] вказують, що евтектичне перетворення в системі відбувається при температурі 1473 К та вміст бору складає 17,0 \% (ат.), автори роботи [4] зазначають, що перетворення відбувається при температурі 1468 К при вмісті бору 16,4 \% (ат.). Іншу температуру 1452 К вказують автори роботи [5], в роботі [6] наводять температуру перетворення $1450 \mathrm{~K}$, а в роботі [7] - $1447 \mathrm{~K}$ та вміст бору 17,0 \% (ат.). В роботі [8] температура евтектичного перетворення взагалі склала 1421 К. Таким чином, різні автори вказують різну температуру утворення евтектики $\gamma-\mathrm{Fe}_{2}+\mathrm{Fe}_{2} \mathrm{~B}$. В літературі існують методи, що дозволяють розрахувати температуру лінії ліквідусу для бінарних сплавів та використовуються при малому за числовим значенням вмісті легуючих елементів [9-11]. Сплави системи Fе-В з вмістом бору до 17 \% (ат.) є доевтектичними, а 3 вмістом бору в інтервалі 17,0-31,8 \% (ат.) - заевтектичними [1-2]. В доевтектичних сплавах мікроструктура представлена $\gamma$-Fe та евтектикою $\gamma$ - $\mathrm{Fe}+\mathrm{Fe}_{2} \mathrm{~B}$, а в заевтектичних - боридом заліза $\mathrm{Fe}_{2} \mathrm{~B}$ та евтектикою $\gamma-\mathrm{Fe}+\mathrm{Fe}_{2} \mathrm{~B}[1-2]$.

Таким чином, метою даної роботи було визначити температурні дані щодо лінії ліквідусу в залежності від вмісту бору в сплаві та температуру евтектичного перетворення в сплавах системи Fe-B.

\section{МАТЕРІАЛИ ТА МЕТОДИКА ДОСЛІДЖЕНЬ}

Дослідження проводили на зразках з вмістом бору 2,0-4,2 \% (мас.), решта - залізо. Для отримання сплавів систем Fe-B використовували шихту такого складу: залізо карбонільне (з вмістом заліза 99,95\% (мас.)), аморфний бор (з вмістом бору 97,5\% (мас.)). Виплавку зразків проводили в печі Тамана в алундових тиглях в атмосфері аргону. Швидкість охолодження сплавів складала $10 \mathrm{~K} / \mathrm{c}$. Для визначення особливостей фазових перетворень сплавів систем Fе-В провели диференційний термічний аналіз зразків на дериватографі.

Для визначення хімічного складу сплаву використовували хімічний та спектральний аналіз [12]. Мікротвердість різних фазових складових визначали на мікротвердомірі ПМТ-3. Фазовий склад сплавів визначали методом мікрорентгеноспектрального аналізу на мікроскопі JSM-6490, а також за допомогою оптичного мікроскопу «Неофот-21». Рентгеноструктурний аналіз здійснювали на дифрактометрі ДРОН-3 в монохроматизованому $\mathrm{Co}_{\alpha}$ випромінюванні.

\section{РЕЗУЛЬТАТИ ТА ЇХ ОБГОВОРЕННЯ}

Мікроструктура доевтектичних сплавів системи Fe-B представлена дендритами заліза та евтектикою $\gamma+\mathrm{Fe}_{2} \mathrm{~B}$, що підтверджено результатами рентгеноструктурного аналізу (рис. 1а). За результатами диференційного термічного аналізу для сплаву 3 вмістом бору $11,6 \%$ (ат.) утворення кристалів $\gamma$-заліза відбулось при температурі 1541 К, а евтектики - 1535 К; при вмісті бору 13,4 \% (ат.) утворення кристалів $\gamma$ заліза відбувається при 1529 К, евтектики - 1442 К. Для сплаву з вмістом 16,1% (ат.) відповідні температури складали 1488 К та 1441 К.

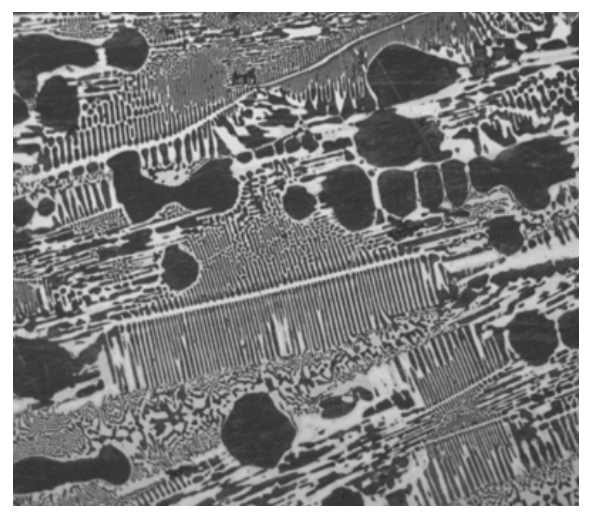

a

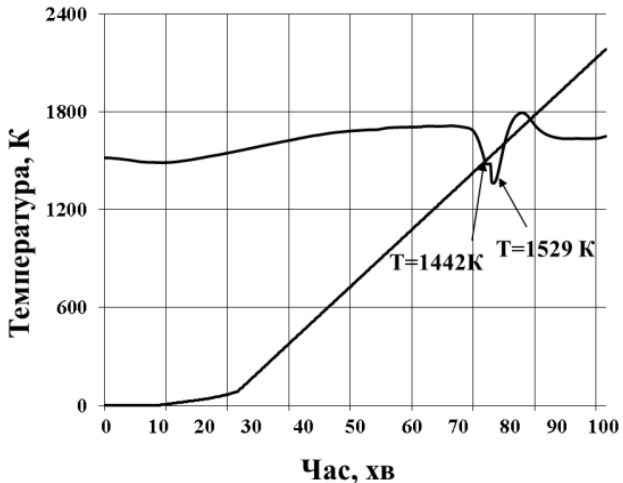

6

Рис. 1. Сплав з вмістом бору $13,4 \%$ (ат.)

a) мікроструктура $\times 500,6)$ диференційний термічний аналіз 
В заевтектичних сплавах системи $\mathrm{Fe}-\mathrm{B}$ первинні бориди $\mathrm{Fe}_{2} \mathrm{~B}$ розташовані в евтектиці $\gamma$-Fe+Fe $2 \mathrm{~B}$ (рис. $2 \mathrm{a}$ ).

Результати диференційного термічного аналізу дозволили визначити температури фазових перетворень в залежності від вмісту бору в сплаві, а саме: при вмісті бору 18,0 \% (ат.) утворення первинних кристалів відбулось при температурі 1498 К, а евтектики - 1442 К; при вмісті 18,7 \% (ат.) утворення первинних кристалів відбувалось при 1533 К, а евтектики - при 1441 К, відповідно (рис. 2, б).

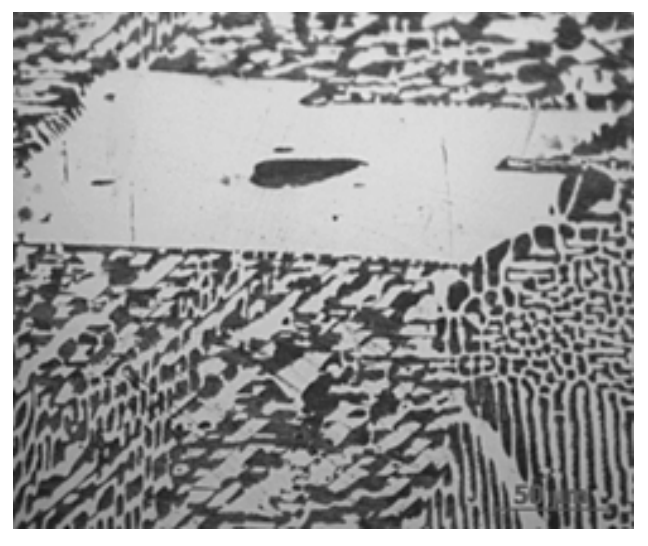

a

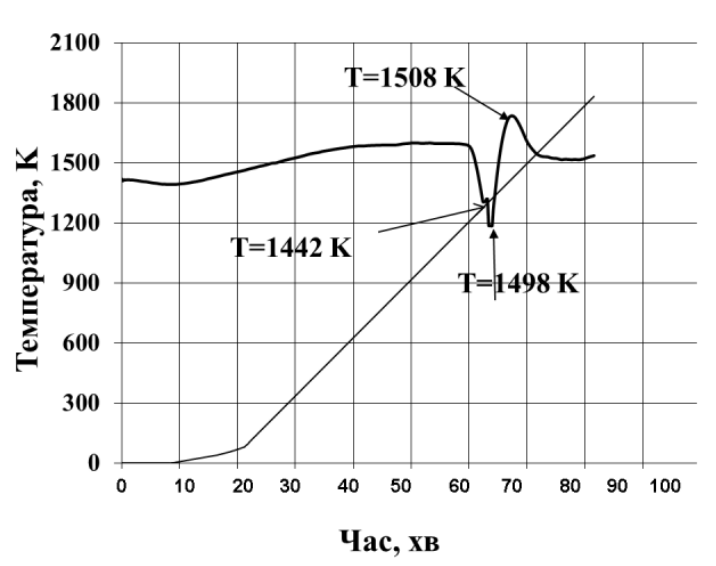

б

Рис. 2. Сплав з вмістом бору $18,0 \%$ (ат.)

a) мікроструктура $\times 500$, б) диференційний термічний аналіз

Таким чином, температура евтектичного перетворення за результатами диференційного термічного аналізу в досліджуваних сплавах склала $1441 \mathrm{~K}$.

Слід зазначити, що температури фазових перетворень, отримані за результатами диференційного термічного аналізу, добре корелюють з результатами, наведеними авторами [6-7].

Як відомо, для отримання рівняння лінії ліквідусу необхідне виконання умови рівності хімічних потенціалів $j$-го компонента в рідкому та твердому станах $\mu_{i}=\mu_{j}$ [13].

Для знаходження лінії ліквідусу для евтектичного перетворення було отримано рівняння вільної енергії для аустеніту та рідини (ліва гілка діаграми стану $\mathrm{Fe}-\mathrm{B})$, бориду $\mathrm{Fe}_{2} \mathrm{~B}$ та рідини сплаву (права гілка діаграми стану Fе-В), відповідно.

\section{Розрахунок вільної енергії аустеніту з урахуванням першого ступеня наближення високотемпературного розвинення термодинамічного потенціалу бінарного сплаву}

Для отримання вільної енергії аустеніту було застосовано квазіхімічний метод [14]. Кристалічна решітка ГЦК має октаедричні та тетраедричні пори. На елементарну комірку ГЦК решітки припадає 4 атоми. Атом бору, який розташований в октаедричній порі, оточений 6 сусідніми атомами заліза. Атоми заліза знаходяться на відстані $a / 2$ від атому бору, де $a$ - параметр решітки $\gamma$-заліза. Тетрагональна пора в аустеніті має радіус $0,22 r$, що замалий для занурення атому бору. На кожен атом елементарної комірки припадає одна октаедрична пустота [15].

При розрахунку термодинамічних функцій фаз для високотемпературної області було враховано внесок першого ступеня наближення високотемпературного розвинення термодинамічного потенціалу бінарного сплаву у вигляді нескінченного ряду за ступенями 1/Т [16].

Енергія взаємодії між елементами $v_{F e B}$ залежить від температури. Температурну залежність енергії взаємодії між елементами представимо як $v_{F e B}=a+b T+c T \ln T$.

Дані енергії взаємодії між компонентами в фазі було взято з робіт [5, 14-15].

Таким чином, залежність вільної енергії аустеніту від температури має наступний вигляд:

$$
F=-\sum_{i=1}^{6} N_{\mathrm{Fe}} N_{\mathrm{B}} v_{\mathrm{FeB}}-k T\left(2 N_{\mathrm{Fe}}\left(\ln 2 N_{\mathrm{Fe}}-1\right)-N_{\mathrm{B}}\left(\ln N_{\mathrm{B}}-1\right)\right)-\frac{v_{\mathrm{Fe} B}^{2} N_{\mathrm{Fe}}^{2} N_{\mathrm{B}}^{2}}{2 Z T R},
$$

де $Z$ - координаційне число $(Z=12)$ [15]. $\left(1-N_{\mathrm{Fe}}\right)$.

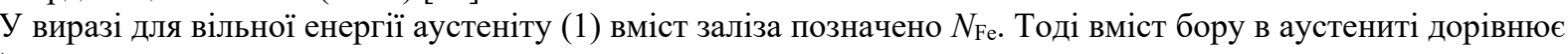

Таким чином, вільну енергію аустеніту (1) з урахуванням зазначених припущень можна визначити як

$F=-\sum_{i=1}^{6} N_{\mathrm{Fe}}\left(1-N_{\mathrm{Fe}}\right) \nu_{\mathrm{FeB}}-k T\left(N_{\mathrm{Fe}}\left(\ln N_{\mathrm{Fe}}-1\right)-\left(1-N_{\mathrm{Fe}}\right)\left(\ln \left(1-N_{\mathrm{Fe}}\right)-1\right)\right)-\frac{v_{\mathrm{FeB}}^{2} N_{\mathrm{Fe}}^{2}\left(1-N_{\mathrm{Fe}}\right)^{2}}{2 Z T R}$ 
Визначимо хімічний потенціал заліза в фазі за відомою формулою [16]:

$$
\begin{gathered}
\mu=-6\left(1-N_{\mathrm{Fe}}\right)(a+b T+c T \ln T)+6 N_{\mathrm{Fe}}(a+b T+c T \ln T)- \\
-k T\left(\ln \left(1-N_{\mathrm{Fe}}\right)+\frac{N_{\mathrm{Fe}}}{1-N_{\mathrm{Fe}}}-\ln \left(1-N_{\mathrm{Fe}}\right)+1\right)-\frac{(a+b T+c T \ln T)^{2} N_{\mathrm{Fe}}\left(1-N_{\mathrm{Fe}}\right)^{2}}{Z R T}+ \\
+\frac{(a+b T+c T \ln T)^{2} N_{\mathrm{Fe}}{ }^{2}\left(1-N_{\mathrm{Fe}}\right)}{Z R T} .
\end{gathered}
$$

Розрахунок вільної енергії розплаву з урахуванням першого ступеня наближення високотемпературного розвинення термодинамічного потенціалу бінарного сплаву

Для розплаву на елементарну комірку припадає в середньому 11 атомів [14-16].

Вільну енергію розплаву з застосуванням квазіхімічного методу визначимо, як

$$
F=-\sum_{i=1}^{11} N_{\mathrm{Fe}} N_{\mathrm{B}} v_{\mathrm{FeB}}-k T\left(N_{\mathrm{Fe}}\left(\ln N_{\mathrm{Fe}}-1\right)-N_{\mathrm{B}}\left(\ln N_{\mathrm{B}}-1\right)-N_{\mathrm{Fe}}\left(\ln N_{\mathrm{Fe}}-1\right)\right)-\frac{v_{\mathrm{FeB}}^{2} N_{\mathrm{Fe}}^{2} N_{\mathrm{B}}^{2}}{2 Z T R} .
$$

У виразі для вільної енергії (1) вміст заліза позначено $N_{\mathrm{Fe}}$. Тоді вміст бору в розплаві дорівнює $\left(1-N_{\mathrm{Fe}}\right)$.

Таким чином, вільну енергію аустеніту з урахуванням зазначених припущень можна визначити як

$$
F=-\sum_{i=1}^{11} N_{\mathrm{Fe}}\left(1-N_{\mathrm{Fe}}\right) \nu_{\mathrm{FeB}}-k T\left(N_{\mathrm{Fe}}\left(\ln N_{\mathrm{Fe}}-1\right)-\left(1-N_{\mathrm{Fe}}\right)\left(\ln \left(1-N_{\mathrm{Fe}}\right)-1\right)\right)-\frac{v_{\mathrm{FeB}}^{2} N_{\mathrm{Fe}}\left(1-N_{\mathrm{Fe}}\right)}{2 Z T R} .
$$

Хімічний потенціал заліза в розплаві:

$$
\begin{gathered}
\mu=-11\left(1-N_{\mathrm{Fe}}\right)(a+b T+c T \ln T)+11 N_{\mathrm{Fe}}(a+b T+c T \ln T)- \\
-k T\left(\ln \left(1-N_{\mathrm{Fe}}\right)+\frac{N_{\mathrm{Fe}}}{1-N_{\mathrm{Fe}}}-\ln \left(1-N_{\mathrm{Fe}}\right)+1\right)-\frac{(a+b T+c T \ln T)^{2} N_{\mathrm{Fe}}\left(1-N_{\mathrm{Fe}}\right)^{2}}{Z R T}+ \\
+\frac{(a+b T+c T \ln T)^{2} N_{\mathrm{Fe}}{ }^{2}\left(1-N_{\mathrm{Fe}}\right)}{Z R T} .
\end{gathered}
$$

\section{Розрахунок вільної енергії бориду $\mathrm{Fe}_{2} \mathrm{~B}$ з урахуванням першого ступеня наближення} високотемпературного розвинення термодинамічного потенціалу бінарного сплаву

Розташування атомів бору в решітці бориду $\mathrm{Fe}_{2} \mathrm{~B}$ умовно можна розділити на дві підрешітки. Перша підрешітка - розташування атомів бору, які мають вісім найближчих атомів заліза на відстані $2,17 \AA$ підрешітку умовно розділили на дві. В першій два атоми розташовані на відстані $2,12 \AA$, а в другій чотири атоми - на відстані 3,61 А́ один від одного. Як відомо, фаза $\mathrm{Fe}_{2} \mathrm{~B}$ містить 32,5 \% (ат.) бору [15].

Вільну енергію бориду $\mathrm{Fe}_{2} \mathrm{~B}$ можна визначити за формулою $F=E-k T \ln W$, де $E$ - внутрішня енергія фази $\mathrm{Fe}_{2} \mathrm{~B}, W$ - термодинамічна вірогідність розміщення атомів у вузлах кристалічної решітки бориду, $k=1,38 \cdot 10^{-23}$ Дж/К - стала Больцмана, $T$ - абсолютна температура.

Взаємодію атомів Fе-В та В-В можна врахувати наступним чином: $v_{\mathrm{FeB}}$ - енергії взаємодії пар атомів та $v_{\mathrm{BB}}$ - для шести атомів бору, розташованих на відстані 3,14 А́. Для числових значень енергії взаємодії пар атомів використовували результати, наведені в роботі [17].

$$
F=-\sum_{i=1}^{8} N_{\mathrm{Fe}} N_{\mathrm{B}} v_{\mathrm{FeB}}-\sum_{i=1}^{6} N_{\mathrm{B}} N_{\mathrm{B}} v_{\mathrm{BB}}-k T\left(N_{\mathrm{Fe}}\left(\ln N_{\mathrm{Fe}}-1\right)-N_{\mathrm{B}}\left(\ln N_{\mathrm{B}}-1\right)\right)-\frac{v_{\mathrm{FeB}}^{2} N_{\mathrm{Fe}}^{2} N_{\mathrm{B}}^{2}}{2 Z T R},
$$

де $Z$ - координаційне число, яке для бориду дорівнює $Z=12$ [12], $N=N_{\mathrm{Fe}}+N_{\mathrm{B}}, N_{\mathrm{Fe}}$ - кількість атомів заліза, $N_{\text {в }}$ - кількість атомів бору, відповідно. Сумарна кількість атомів в сполуці $\sum_{i=1}^{2} N_{i}=1$. Позначимо міст бору в бориді $\left(1-N_{\mathrm{Fe}}\right)$. Температурну залежність енергії взаємодії між елементами представимо як $v_{F e B}=a+b T+c T \ln T$ та $v_{B B}=a_{1}+b_{1} T+c_{1} T \ln T$.

Вільну енергію для бориду визначимо як:

$$
\begin{gathered}
F=-8 N_{\mathrm{Fe}}\left(1-N_{\mathrm{Fe}}\right)(a+b T+c T \ln T)-6\left(1-N_{\mathrm{Fe}}\right)^{2}\left(a_{1}+b_{1} T+c_{1} T \ln T\right)-k T\left(\left(N_{\mathrm{Fe}} \ln \left(N_{\mathrm{Fe}}-1\right)-\right.\right. \\
\left.-\left(1-N_{\mathrm{Fe}}\right)\left(\ln \left(1-N_{\mathrm{Fe}}\right)-1\right)\right)-\frac{(a+b T+c T \ln T)^{2} N_{\mathrm{Fe}}^{2}\left(1-N_{\mathrm{Fe}}\right)^{2}}{2 Z R T} .
\end{gathered}
$$


Хімічний потенціал заліза в бориді має вигляд:

$$
\begin{gathered}
\mu=-8 N_{\mathrm{Fe}}\left(1-N_{\mathrm{Fe}}\right)(a+b T+c T \ln T)+8 N_{\mathrm{Fe}}(a+b T+c T \ln T)+12\left(1-N_{\mathrm{Fe}}\right)(a+b T+c T \ln T)+ \\
+R T\left(\ln \left(1-N_{\mathrm{Fe}}\right)+\frac{N_{\mathrm{Fe}}}{1-N_{\mathrm{Fe}}}-\ln \left(1-N_{\mathrm{Fe}}\right)-1\right)-\frac{(a+b T+c T \ln T)^{2} N_{\mathrm{Fe}}\left(1-N_{\mathrm{Fe}}\right)^{2}}{Z R T}+ \\
+\frac{(a+b T+c T \ln T)^{2} N_{\mathrm{Fe}}^{2}\left(1-N_{\mathrm{Fe}}\right)}{Z R T} .
\end{gathered}
$$

Таким чином, для отримання лінії ліквідусу для доевтектичних та заевтектичних сплавів були знайдені розв'язки рівнянь (3) та (6), та (6) і (9) в чисельному вигляді, відповідно. Результати наведено на рис. 3.

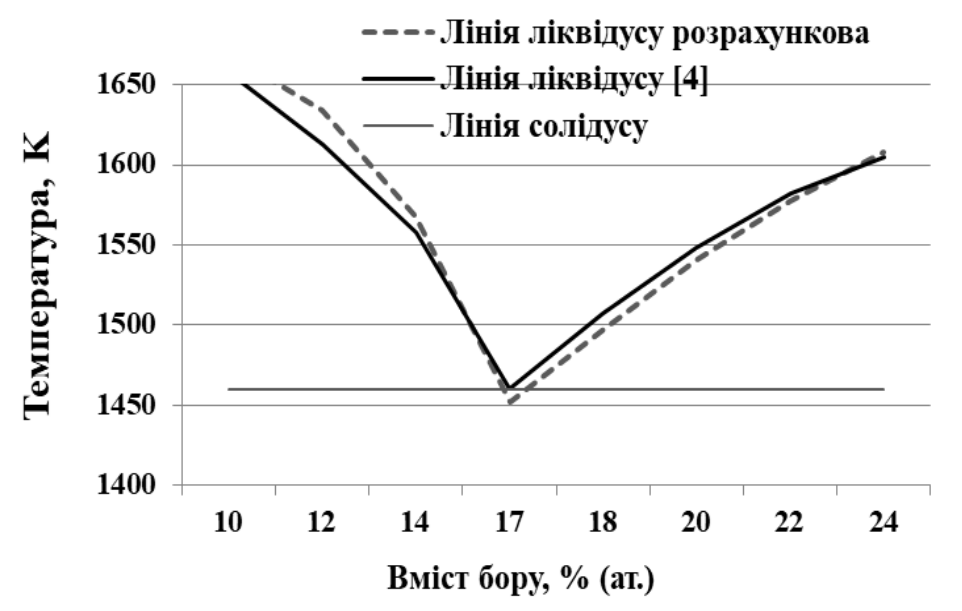

Рис. 3. Діаграма стану системи Fе-B

Згідно отриманих результатів температура евтектики становить 1452 К при вмісті бору 16,8 \% (ат.), що співпадає з результатами авторів [5-6] та дещо нижча порівняно з даними інших авторів [1-4]. Розбіжність отриманих результатів з результатами інших авторів можна пояснити впливом легуючих елементів в шихті сплавів та переохолоджуваністю фаз [1-2].

\section{ВИСНОВКИ}

Вперше 3 застосуванням квазіхімічного методу та 3 урахуванням першого ступеня наближення високотемпературного розвинення термодинамічного потенціалу бінарного сплаву отримано вирази для вільної енергії розплаву бінарного сплаву $\mathrm{Fe}-\mathrm{B}$, аустеніту та бориду $\mathrm{Fe}_{2} \mathrm{~B}$. Побудовано лінії ліквідусу при кристалізації доевтектичних та заевтектичних сплавів системи Fe-B. Визначено температуру евтектичного перетворення та вміст бору при цьому перетворенні, які корелюють з результатами експериментів та даними інших авторів.

N.Yu. Filonenko (D) https://orcid.org/0000-0003-1219-348X

\section{ORCID IDs}

\section{СПИСОК ЛІТЕРАТУРИ}

[1]. G.V. Samsonov, T.I. Serebryakova and V.A. Neronov, Бориды [Borides], (Moscow, Atomizdat, 1999), p. 220. (in Russian)

[2]. N.P. Lyakishev, Yu.L. Pliner and S.I. Lappo, Борсодержащие стали и сплавы [Boron- bearing steels and alloys] (Moscow, Metallurgiya, 1986), p. 191. (in Russian)

[3]. Yu.B. Kuzma, N.F. Chaban, Двойные и тройные системы, содержащие бор: Справочник [Boron-bearing binary and ternary systems], (Moscow, Metallurgiya, 1990), p. 317. (in Russian)

[4]. H. Okamoto, Journal of Phase Equilibria and Diffusion. 25(3), 297-298 (2004).

[5]. M. Palumbo, G. Cacciamani, E. Bosco and M. Baricco, Intermetallics. 11, 1293-1299 (2003).

[6]. N.P. Lyakishev, Диаграммы состояния двойных металлических систем: Справочник [Phase Diagrams of Binary Metal Systems: Handbook], (Moscow, Mashinostroenie, 2001), p. 498. (in Russian)

[7]. A.E. Vol, Строение и свойства металлических систем [Structure and properties of binary metal systems], (Moscow, Gosudarstvennoe izdatelstvo Fiziko-matematicheskoy IIteraturyi, 1959), p. 856. (in Russian)

[8]. M. Hansen, K. Adderko Структура двойных сплавов [Structure of binary alloys], (Moscow, Gosudarstvennoe nauchnotehnicheskoe izdatelstvo literatury po chernoy i tsvetnoy metallurgii, 1962), p. 354. (in Russian)

[9]. J. Kavulicova, D. Ivanova, J. Durisin, G. Sucik and M. Srobian, Kovove Mater. 44(3), 181-184 (2006).

[10]. M.B. Djurdjevic, S. Manasijevic, Z. Odanovic and N. Dolic, Advances in Materials Science and Engineering. 1, 1-8 (2013).

[11]. K. Gryc, B. Smetana, M. Tkadleckov, M. Žaludov, K. Michalek, L. Socha, J. Dobrovsk and K. Janiszewski, Metabk. 53(3), 295-298 (2014). 
[12]. S.V. Tverdokhlebova, Visnyk Dnipropetrovskogo nacionalnogo universitetu. Serija Fizika. Radioelektronika. 14(12/1), 100-104 (2007).

[13]. E.V. Kalashnikov, Journal of Technical Physics. 67(4), 7-12 (1997). (in Russian)

[14]. V.A. Kozheurov Статиская термодинамика [Statistical thermodynamics], (Moscow, Metallurgiya, 1975), p. 175. (in Russian)

[15]. M.P. Shaskolskaya, Кристаллография [Crystallography], (Moscow, Vyisshaya shkola, 1984), p. 376. (in Russian)

[16]. L. Zhirifalko Статистическая физика твердого тела [Statistical Solid State Physics], (Moscow, Mir, 1975), p. 376. (in Russian)

[17]. T. van Rompaey et al, J. Alloys Compounds. 334, 173-181 (2002).

[18]. B. Halemans et al, Z. Metallkd. 85(10), 676-682 (1994).

[19]. V.V. Sychev Дифференциальные уравнения термодинаміки [Differential equations of thermodynamics], (Moscow, Vyisshaya shkola, 1991), p. 220. (in Russian) 